\title{
A inclusão de universitários com deficiência em cursos de Educação Física na cidade de Maceió/AL
}

\author{
David dos Santos Calheiros \\ Neiza de Lourdes Frederico Fumes
}

Resumo: Nos anos mais recentes, uma crescente participação de pessoas com deficiência a ter acesso à Educação Superior. Esse processo desafia e provoca mudanças dentro e fora dos muros das Instituições de Ensino Superior (IES). Por esta razão, nos propomos nesta pesquisa de casos múltiplos, de abordagem qualitativa, a entender o processo de inclusão de universitários com deficiência em cursos presenciais de Graduação em Educação Física da cidade de Maceió/AL, utilizando como instrumento de coleta de dados a entrevista semiestruturada. Os participantes desse estudo foram os/as próprios/as universitários/as com deficiência e seus respectivos coordenadores de curso. Para o tratamento dos dados coletados, utilizamos a análise de conteúdo, especificamente a temática. Para aplicá-la, fizemos uma leitura exaustiva dos materiais recolhidos, a fim de elencarmos um delineamento dos temas importantes para o estudo. Em seguida, houve exploração dos potenciais de codificações baseadas em critérios temáticos. Os resultados dessa pesquisa assinalam que apenas 03 (1 pública e 2 privadas) das 20 IES (presenciais) da cidade de Maceió/AL ofertavam cursos de Educação Física, em 2009/2010. Destas 03 IES, verificamos, através de visitas in loco, que apenas as 2 instituições privadas - denominadas, neste estudo, de Instituição "A" e Instituição "B"- possuíam universitários com deficiência, sendo que na instituição "A" havia 02 universitários com deficiência e na instituição "B", 03 universitários/as com deficiência. Estes 05 universitários/ as foram convidados/as a participar da pesquisa, bem como os seus respectivos coordenadores de curso: 02 no total, um de cada instituição, os quais aceitaram e declararam isso assinando o Termo de Consentimento Livre e Esclarecido (TCLE). Os resultados apontaram que, embora o processo de inclusão esteja em andamento e a participação do universitário/a com deficiência na Educação Superior seja mais expressiva do que era anos atrás, a sua permanência estava condicionada aos seus próprios esforços e à ajuda de colegas de classe. Essa condição era decorrente das inúmeras barreiras que ainda se mantinham presentes no espaço educacional, deixando-o/a mais vulnerável à exclusão. Dessa forma, é crucial que as instituições pesquisadas (re)pensem a forma com que têm encarado a inclusão no ambiente da sua instituição e que, além disso, planejem e executem ações que contribuam para esse processo em seu estabelecimento de ensino. Assim, acreditamos que a instituição estudada estaria mais preparada para garantir o processo de ensino-aprendizagem do universitário com deficiência em uma perspectiva da educação inclusiva.

Palavras-chave: Inclusão. Universitários com deficiência. Educação Superior.

\section{The inclusion of students with disabilities in Physical Education underdegree courses in the city of Maceió-AL, Brazil}

\footnotetext{
Abstract: In recent years, the access of people with disability has increased in college education. This process defies and provokes changes inside and outside the wall of College Education Institution (CEI). Because this reason, we propose ourselves, in this research of cases multiples and qualitative approach, to understand the inclusion process of students with disability in Physical Education underdegree courses in the city of Maceio/AL, using instrument of gathering data a semi-structured interview. In this study, the participants were students with disability and their respective course coordinators. For the analysis of data we used the contents analysis, specifically the thematic.
} 


\begin{abstract}
We made an exhaustive reading of the collected materials and we identified the important themes for the study. After this, we codified based on thematic criteria. The results reported that only 03 ( 1 public and 2 private) of $20 \mathrm{CEI}$ in the city of Maceio/AL offers Physical Education Teaching Courses in 2009/2010. Theses 03 CEI, we verified, through of visits in loco that only two private institutions - they were called in this study of "A" Institution and " $\mathrm{B}$ " Institution - have students with disability - Institution "A" had 02 students and Institution "B" had 03 ones. These 05 students with disability were invited to take part in the research, as well their respective course coordinators -02 in the total, one from each institution. All of them accepted the invitation and signing the Informed Consent Form (ICF). The results showed that although the inclusion process was going on and the participation of students with disability in the Physical Education underdegree courses was more expressive than years ago, their permanence was conditioned to their own efforts and help of classmates. This condition was due to several barriers that still existed in the educational space, leaving them more vulnerable to exclusion. Thus, it was crucial that the institutions surveyed (re)think the form that has seen the inclusion of the environment in your institution, furthermore, plan and execute actions that contribute to this process in their educational establishment. Thus, we believe that the studied institution would be more prepared to make teaching-learning students with disability in inclusive education perspective.
\end{abstract}

Key words: Inclusion. Students with disability.College Education.

\title{
Introdução
}

O/A universitário/a com deficiência e a sua inclusão na educação superior desafiam e provocam mudanças dentro e fora dos muros das Instituições de Ensino Superior. Dizemos isso porque, historicamente, esse público esteve alijado do acesso à educação e, muitas das vezes, quando a sua participação ocorria, havia certa restrição das matrículas na educação básica (VARGAS, 2006), sendo, portanto, o estigma social uma das objeções que, por muito tempo, afastou e ainda afasta as pessoas com deficiência de terem acesso à educação e de evoluírem no seu processo de escolarização. Com relação ao estigma social, Magalhães et al. (2008, p. 2-3) entendem-no como "a concepção social sobre atributos diferentes em relação ao que é considerado padrão, como uma marca que determina alguns sujeitos como inferiores aos demais. É o modo como a sociedade vê, concebe e lida com a diferença".

Diante dessa realidade em transformação, entendemos que é essencial que as IES reflitam sobre seu papel no atendimento do universitário/a com deficiência, para que todos possam ter as mesmas oportunidades de participar com sucesso no sistema educacional. Como afirmam Dias, Silveira e Musis (2008, p. 4), "as pessoas com deficiência têm chegado às universidades e estas instituições têm encontrado inúmeras dificuldades e dúvidas com relação ao que precisam prover e à forma como devem se estruturar para receber esses alunos".

Para ilustrar esse novo quadro, tomamos como base o número de universitários/as com deficiência matriculados/as em cursos de graduação em Instituições de Ensino Superior (IES) brasileiras, o qual tem aumentado consideravelmente 
A inclusão de universitários com deficiência em cursos de Educação Física na cidade de Maceió/AL jurídico

nos últimos anos. De modo específico, entre 2000 e 2010, houve um crescimento importante passando de 2.173 para 20.287 universitários/as, com alguma deficiência, matriculados/as, o que representa um crescimento percentual de $933,6 \%$ (BRASIL, 2012a). Importa destacar que as matrículas nas instituições privadas são a maioria: 13.403 do total, em detrimento das realizadas em instituições públicas que somam 6.884 universitários com deficiência.

De uma maneira específica, nos cursos de graduação em Educação Física, o Censo Educacional aponta a presença de 432 universitários, com deficiência, matriculados em Instituições de Ensino Superior de todo o Brasil (BRASIL, 2010). Deste total, 129 universitários com deficiência possuíam matrículas em IES públicas e 303 universitários com deficiência em IES privadas.

Esses indicadores apontam para a ampliação do acesso à educação superior do/a aluno/a com deficiência. Contudo, "é importante salientar que a 'quantidade' não é o único fator relacionado à inclusão, mas que é fundamental garantir qualidade na educação, tanto nas instituições superiores, quanto nos demais níveis e modalidades de ensino" (SANTOS; VIANA; FUMES, 2008, p. 8).

Em Maceió/AL, o crescimento no número de matrículas de universitários/ as com deficiência a frequentar a educação superior também é uma realidade que está em consonância com o que ocorre no país. No entanto, os resultados desse processo de inclusão não são satisfatórios se pensarmos em uma educação que atenda efetivamente a todos/as os/as universitários/as. Esta realidade foi verificada por outras pesquisas realizadas na cidade de Maceió/AL que constataram ser a inclusão de universitários/as com deficiência em Maceió/ AL ainda algo muito recente, sendo prejudicada pela falta de acessibilidade, barreiras atitudinais, ausência de formação e precarização da atividade docente, assim como, insuficiência de recursos que possibilitem a permanência desse/a universitário/a com qualidade no sistema educacional (CALHEIROS; FUMES, 2011; SANTOS, 2011).

No entanto, de maneira mais abrangente, se sabe que a falta de informações de gestores/a), professores/as e demais membros de uma IES acerca das necessidades dos universitários/as com deficiência no que se refere aos métodos de ensino, materiais didáticos adaptados e uma comunicação satisfatória entre universitário/a - professor/a promove, em grande escala, a impossibilidade de acesso, permanência e sucesso no ensino superior pelo/a universitário/a com deficiência, mesmo que nos dias atuais já tenhamos universitários/as cursando e concluindo esse nível de ensino (ANDRADE; PACHECO; FARIAS, 2006).

Não obstante, além da necessidade de garantir o acesso e a permanência na Educação Superior da pessoa com deficiência, entendemos que é preciso 
garantir também sucesso e aprendizagem educacional, pois, no caso específico da educação superior não é somente a conclusão de um curso de nível superior que interessa aos então universitários, seja com ou sem deficiência. Há também o anseio de se tornar um profissional qualificado e capaz de responder aos desafios impostos pelo mercado de trabalho (CARDOSO; BRAGA, 2009).

Levando em consideração esses aspectos, propusemo-nos analisar o processo de inclusão de universitários/as com deficiência em cursos de Educação Física de instituições de ensino superior da cidade de Maceió/AL. Mais especificadamente, analisaremos a opinião de universitários/as com deficiência e de coordenadores de cursos de IES de Educação Física acerca do processo de inclusão desses universitários/as na educação superior, mais particularmente na sua instituição.

\section{Aspectos metodológicos}

Neste estudo, optamos por utilizar uma abordagem qualitativa de pesquisa, em virtude de que esse tipo de investigação está interessado na perspectiva da construção social dos participantes acerca de suas práticas cotidianas relativas à questão da pesquisa e por considerar o diálogo do pesquisador/a com os/as participantes do estudo como parte explícita da produção de conhecimento (FLICK, 2009). Além disso, essa pesquisa utiliza uma estratégia de estudo de caso $^{1}$, cujo método, de acordo com Martins (2008, p. 10), "é próprio para a construção de uma investigação empírica que pesquisa fenômenos dentro de seu contexto real - pesquisa naturalística - com pouco controle do pesquisador sobre eventos e manifestações do fenômeno". Mais especificamente, realizaremos um estudo de casos múltiplos, o qual permite investigar, de forma simultânea, diferentes realidades envolvendo vários indivíduos e várias instituições (ALVES-MAZZOTTI, 2006).

Para a coleta dos dados utilizamos a entrevista semiestruturada, com caráter reflexivo. De acordo com Yunes e Szymanski (2005), a proposta da entrevista reflexiva supõe uma condição em que é pertinente entender a subjetividade da fala do/a entrevistado/a, o que favorece a construção de um novo conhecimento, nos limites da representatividade da fala e na busca de uma horizontalidade nas relações de poder.

Para a definição dos/as participantes da pesquisa fizemos, inicialmente, junto ao Sistema e-MEC (BRASIL, 2012b), um mapeamento das Instituições

1 Os estudos de casos mais comuns são aqueles que se restringem apenas a uma unidade específica, porém é necessário mencionar que existem estudos de casos que abordam múltiplas unidades - múltiplos casos, de forma concomitante (ALVES-MAZZOTTI, 2006). 
de Ensino Superior de Maceió/AL cadastradas no Ministério da Educação. Esse procedimento nos possibilitou constatar a presença de 20 IES que funcionam na modalidade presencial e 18 IES que trabalham no sistema de Educação à Distância (EAD). Em seguida, identificamos 3 IES (1 pública e 2 privadas) com cursos de graduação em Educação Física, na modalidade presencial e com sede na cidade de Maceió/AL. Destas IES, verificamos, por meio de visitas in locu, que apenas as 2 instituições privadas possuíam universitários com deficiência, sendo que na instituição " $A$ " havia 02 universitários e na instituição " $B$ " havia 03 universitários com deficiência. Além destes 05 universitários/as, participaram da pesquisa 02 coordenadores/as de curso, um de cada instituição.

Uma vez contatados/as os/as universitários/as com deficiência e os seus respectivos coordenadores(as) do curso de Educação Física, esclarecemos as questões éticas da pesquisa envolvendo seres humanos - inclusive, apresentando o parecer de aprovação pelo Comitê de Ética da Universidade Federal de Alagoas, sob o n ${ }^{\circ}$ 010620/2009 - 44. Iniciamos, então, as entrevistas, as quais foram realizadas individualmente e gravadas (em áudio) na íntegra, sendo logo depois transcritas literalmente para posterior análise dos dados. No caso dos universitários com surdez e parcialmente surdos, tivemos o auxílio de intérpretes de Libras e a tradução do intérprete foi gravada e posteriormente utilizada para a análise dos dados.

Em relação à análise dos dados obtidos, cabe-nos destacar que confrontamos as perspectivas dos/as coordenadores/as e as dos/as universitários/as com deficiência, em busca de entender, com maior profundidade, o processo de inclusão de universitários com deficiência na educação superior, mais particularmente na sua instituição. Para tanto, utilizamos a análise de conteúdo, especificadamente a temática, um dos procedimentos clássicos para analisar material de origem textual.

De acordo com Bardin (2011, p. 135), esse tipo de análise temática“[...] consiste em descobrir os núcleos de sentidos que compõem uma comunicação cuja presença ou frequência de aparição, pode significar alguma coisa para o objetivo analítico escolhido". Além disso, a autora menciona que uma das características essenciais desse método é a utilização de categorias que, de um modo particular, tende a valorizar o material a ser analisado, principalmente por essa análise permitir a contextualização com os fatos sociais e históricos nos quais foram produzidos. Para aplicá-la, fizemos uma leitura exaustiva dos materiais recolhidos, a fim de delinearmos os temas importantes para o estudo. Em seguida, houve exploração dos potenciais de codificações baseadas em critérios temáticos. 
Desses procedimentos, levantamos as seguintes categorias: I. O caso da inclusão de universitários/as com deficiência na IES “A"; II. O caso da inclusão de universitários/as com deficiência na IES "B”, os quais serão discutidos no decurso deste texto.

\section{Resultados e discussão}

Os resultados obtidos com essa pesquisa serão apresentados e discutidos obedecendo à sequência de categorias anteriormente referidas.

\section{O caso da inclusão de universitários/as com deficiência na IES "A"}

A Instituição de Ensino Superior "A" é uma faculdade privada de Maceió/ AL que oferece cursos de graduação em Pedagogia, Fisioterapia e Educação Física (Licenciatura e Bacharelado). Assim como o caso de muitas outras IES do Brasil, a inclusão educacional no seio dessa instituição é um fator recente e que demanda certa preocupação dos órgãos administrativos. Para termos uma compreensão mais detalhada desse atual processo, convém apresentar, inicialmente, alguns pormenores dos atores que estão envolvidos nessa trama e que fizeram parte dessa pesquisa:

\section{Quadro 1 - Caracterização dos participantes da Instituição "A"}

\begin{tabular}{|c|c|c|c|}
\hline IES & Coordenador & Universitário/ldade & Deficiência \\
\hline \multirow{2}{*}{ "A" } & Bernardo & Wesley -21 anos & Parcialmente Surdo \\
\cline { 3 - 4 } & & Martin -24 anos & Surdez \\
\hline
\end{tabular}

Como pudemos perceber, a referida IES "A" possuía dois universitários, Wesley $^{2}$ e Martin $^{3}$, que possuem comprometimentos funcionais auditivos. Contudo, é importante mencionarmos que, embora tais universitários tivessem o acesso à educação superior, o atendimento das suas necessidades educacionais especiais não era contemplado em sua concretude. Com isso, ficavam mais expostos e vulneráveis ao processo de exclusão educacional.

Tais dificuldades relacionadas ao não atendimento das necessidades educacionais especiais puderam ser percebidas ainda no processo de ingresso na IES em questão. De uma maneira particular, um dos universitários, então candidato, relatou que não foi atendida a sua solicitação de um intérprete de Libras para

2 Utiliza o Português como primeira língua.

3 Utiliza a Libras como primeira língua. 
A inclusão de universitários com deficiência em cursos de Educação Física na cidade de Maceió/AL jurídico

a realização da prova, conforme havia demandado em sua inscrição para o processo seletivo. Vejamos isto no excerto a seguir:

Algumas faculdades não dão condições de terem intérpretes de Libras. Aqui [na faculdade] foi uma confusão, porque na hora da prova não tinha lá uma pessoa capacitada para interpretar a prova de vestibular para ingressos [...] (Universitário Martin).

Como podemos constatar, a Instituição " $A$ " não buscou garantir os meios necessários para que o candidato pudesse realizar a prova de seleção em igualdade de condições com os demais candidatos. As dificuldades enfrentadas pelo universitário Martin foram percebidas pelo seu colega de curso e também participante desta pesquisa, Wesley, embora o próprio não tivesse solicitado nenhum recurso especial e não tivesse posto nenhuma objeção ao processo seletivo, conforme podemos visualizar no recorte a seguir:

Pelo que vi o meu [ingresso à faculdade] foi bom. [...] Mas, o meu colega surdo [Universitário Martin] não o avaliaram tão bem, porque ele tem dificuldade para passar para o papel, escrever, até na sala ele tem dificuldade [...] (Universitário Wesley).

Diante desse cenário, o descompromisso com o provimento de recursos necessários para garantir a acessibilidade ao processo seletivo para ingresso na educação superior prejudicou o universitário com surdez desde o seu primeiro contato com a instituição. No entanto, essa condição foi rechaçada pelo coordenador do curso de Educação Física da instituição "A", que afirmou que seu estabelecimento de ensino atendeu as solicitações requeridas pelo universitário com deficiência, Martin, disponibilizando o recurso humano/ especializado solicitado - intérprete. Vejamos o que ele nos diz:

Bem, para fazer a prova a gente contratou uma pessoa para fazer essa tradução da prova para ele, para facilitar todo esse processo para o aluno. Ele não teve dificuldade em relação à prova. Tivemos uma pessoa exclusiva para atendê-lo na sala. Não havia só ele. Eram três alunos fazendo a mesma prova, mas só um passou. Então, o acesso à nossa instituição, a gente procura deixar isso de uma forma mais simples possivel e até atendendo à legislação vigente (Coordenador Bernardo). 
Diante dessas controvérsias acerca do processo de ingresso à Instituição "A", em termos de acessibilidade, não nos cabe julgar/condenar qualquer um dos sujeitos envolvidos, mas, sim, refletir e intervir junto aos órgãos competentes e a comunidade acadêmica, no sentido de que ela se adeque de forma estrutural, e, assim, crie condições favoráveis a fim de possibilitar o acesso desses/as universitários/as à Educação Superior, conforme o estabelecido no Aviso Circular n²77 (BRASIL, 1996).

Ademais, os resultados dessa pesquisa mostram-nos que as dificuldades e os constrangimentos, vivenciados pelos universitários com deficiência na Instituição " $\mathrm{A}$ ", ultrapassaram o processo seletivo, comprometendo o sucesso acadêmico e, consequentemente, o desempenho desses futuros profissionais. A seguir, apresentamos alguns recortes que ilustram esse fato:

Tive problema na primeira aula. Ficaram [colegas de classe] rindo por causa da minha voz [dificuldade de oralizar] (Universitário Wesley).

Alguns professores de algumas matérias pareciam que tinham medo de chegar perto de mim porque não sabiam se comunicar. Então, pensavam que iriam errar (Universitário Martin).

É bem verdade que, com o passar do tempo e com a convivência, a relação entre os universitários com deficiência e seus colegas de curso e professores/as modificou-se para melhor, tornando-se mais respeitosa e compreensível. Com isto, parte dos/as professores/as refletiu sobre sua prática pedagógica e propôs mudanças, visando à participação efetiva dos universitários com deficiência em suas aulas. Além disso, alguns membros dos órgãos administrativos realizaram um curso básico de Libras financiado pela própria instituição de Ensino Superior "A", a qual também se encarregava de oferecer a disciplina de Libras $^{4}$ como parte integrante da matriz Curricular do curso de Educação Física. Estas ações foram importantes no sentido de melhorar a comunicação com a comunidade surda.

Vejamos algumas dessas mudanças:

No $1^{\circ}$ e $2^{\circ}$ periodos tinham professores que sempre faziam algumas adaptações na aula para eu poder praticar junto com todos os alunos e não ficasse apenas sentado olhando. Os professores pegavam além do apito, algum material como bandeira ou algum pedaço de papel para que eu

4 A inclusão da disciplina de Libras na matriz curricular é legitimada pelo Art. $3^{\circ}$ do Decreto $\mathrm{N}^{\circ} 5.626$, de 22 de dezembro de 2005. 
A inclusão de universitários com deficiência em cursos de Educação Física na cidade de Maceió/AL jurídico

visse o sinal dele na hora da aula prática, faziam também aulas em duplas (Universitário Martin).

Antes, eles [técnicos-administrativos] ficavam meio assim... Acho que é porque eles não conheciam e não tinham nenhum contato com pessoas com deficiência, ficando com o pé atrás na hora de falar comigo, mas hoje em dia mudou, já que alguns funcionários já fizeram curso de Libras ou, também, se comunicam pela escrita no papel (Universitário Martin).

Os meus colegas da graduação foram praticando a Lingua de Sinais e, hoje, todos falam comigo, não só na Libras, mas, também com a escrita. No $6^{\circ}$ periodo tem uma matéria de Libras ai fica mais fácil para o pessoal se comunicar comigo (Universitário Martin).

Essas ações levam-nos a considerar que, a partir do momento em que são garantidas as condições necessárias para o desenvolvimento acadêmico do universitário com deficiência, conforme observamos no caso da Instituição " $A$ ", o processo de inclusão começa a ser efetivado. Contudo, é inevitável mencionarmos que essas ações inclusivas devem acompanhar o/a universitário/a com deficiência no decorrer do seu curso de graduação, isto é, do ingresso à conclusão do curso. Para tanto, é crucial que tais Instituições de Ensino Superior estejam prontas para a prestação desse atendimento. E isso não deve ser encarado como privilégio, mas, sim, como um processo de equiparação das oportunidades de acesso e permanência à educação superior.

\section{O caso da inclusão de universitários/as com deficiência na IES "B"}

A Instituição de Ensino Superior "B", semelhantemente à Instituição de Ensino Superior "A", que foi analisada no caso anterior, era uma Faculdade privada que atuava na formação de profissionais de nível superior, em diversas áreas do conhecimento, e pertencente a um grupo com unidades de ensino espalhadas em diversas unidades federativas. Nos últimos anos, tinha matriculados/ as em seu corpo discente, vários universitários/as com deficiência, sendo que especificamente no curso de Educação Física havia três desses universitários/as. Para uma melhor compreensão acerca desses universitários/as com deficiência e da IES "B", convém exibirmos, no quadro 2 abaixo, algumas informações a mais que lhe permitirão serem caracterizados: 


\section{Quadro 2 - Caracterização dos participantes da Instituição "B"}

\begin{tabular}{|c|c|c|c|}
\hline IES & Coordenador & Universitário/ldade & Deficiência \\
\hline \multirow{2}{*}{ "B" } & Fabrício & Cláudio -30 anos & Deficiência Física \\
\cline { 3 - 4 } & & Lorena -26 anos & Surdez \\
\cline { 3 - 4 } & & Mickaela -21 anos & Surdez \\
\cline { 2 - 4 } & & &
\end{tabular}

De uma maneira geral, os resultados obtidos sobre o processo de inclusão na Instituição "B", por meio das entrevistas realizadas com os/as universitários/as com deficiência e com o coordenador do curso de Educação Física, revelam-nos que a faculdade vinha atuando timidamente na construção de um ambiente inclusivo. Além do mais, suas ações ainda estão muito aquém dos princípios da inclusão, propostos pela Declaração de Salamanca (UNESCO, 1994). Também havia uma defasagem entre as medidas definidas pela Portaria do Ministério da Educação 3.284 (BRASIL, 2003) para assegurar aos universitários com deficiência, condições básicas de acesso à educação superior.

De acordo com os universitários/as com deficiência, as dificuldades relativas à inclusão na Instituição "B" principiaram ainda na realização do processo seletivo, no qual houve segregação dos candidatos, isto é, quem possuía alguma deficiência fazia o exame de seleção em outra sala, separado dos demais candidatos que não apresentavam deficiência. Esta atitude foi sinalizada pela universitária Lorena como sendo preconceituosa, conforme o exposto no fragmento abaixo:

Quando eu fiz o vestibular, separaram surdos e ouvintes. Isso é preconceito. Tem que ter inclusão social (Universitária Lorena).

Este episódio antecipa alguns dos problemas que os/as universitários/as com deficiência iriam enfrentar ao longo de sua formação de nível superior na Instituição "B", os quais deixariam vulneráveis à exclusão e a sua aprendizagem condicionada aos seus próprios esforços e à dependência da ajuda de seus colegas de classe. Logo a seguir, apresentamos alguns desses impasses sofridos pelos universitários/as com deficiência:

[...] Tive problemas porque quando cheguei não tinha intérprete. Tinha um monte de ouvintes que eu não conhecia. Fiquei meio envergonhada. A mulher começou a perguntar cadê o intérprete e então se começou a 
A inclusão de universitários com deficiência em cursos de Educação Física na cidade de Maceió/AL jurídico

exigir da faculdade. O coordenador ficou preocupado. Ele tinha esquecido que eu era surda, ai tive problemas porque tive que assistir aula sem intérprete. Então, os ouvintes me ajudaram na questão da escrita para se comunicar comigo (Universitária Lorena).

Tive dificuldade com as disciplinas: Biologia (três repetências); Natação (duas repetências); Anatomia (duas repetências); Saúde Pública (três repetências); Cinesiologia (três repetências); Gestão (três repetências); e Crescimento/Desenvolvimento (três repetências). Já chorei de desespero e pensei em desistir do curso [Educação Física] por essa dificuldade que tive, mas como é uma coisa que gosto, eu fui devagarzinho, no meu ritmo. [...] Eles [professores] acham que não tenho problema nenhum e que é tudo coisa da minha cabeça, mas melhorei muito, mas é que às vezes me dá um branco na hora da prova. Fico nervoso, tenso, mas graças a Deus estou vencendo aos pouquinhos (Universitário Cláudio).

Esses relatos ilustram as barreiras encontradas na instituição e que limitam o processo de inclusão de uma universitária com surdez e um universitário com deficiência física. No primeiro caso, a ausência de um intérprete de Libras $^{5}$ é o agente que tangencia o desconforto na inviabilização/limitação do acesso à comunicação, aos processos educativos e à informação para a universitária Lorena, deixando-a fadada à exclusão e totalmente dependente da ajuda de outros universitários da sua classe. Esse fato assemelha-se ao de outras Instituições de Ensino Superior, onde a ausência da figura do intérprete de Libras é uma evidência (CRUZ; DIAS, 2009).

No que se refere ao segundo recorte, podemos constatar que o universitário Cláudio apresentava um alto índice de reprovação nas disciplinas curriculares do curso de Educação Física e, embora, ele apresentasse uma deficiência física não podemos desconsiderar que o mesmo também possuía certas necessidades educacionais em termos de aprendizagem de conteúdos curriculares, principalmente aqueles mais teóricos. Estas necessidades eram desconsideradas por parte de seus/suas professores/as. Além do mais, tais professores/as negavam-se a modificar a forma de aplicação dos instrumentos avaliativos. Por exemplo, a substituição da prova escrita em detrimento da prova oral, mesmo sabendo que esta lhe daria melhor oportunidade de expor, no exame avaliativo, os conteúdos aprendidos. O fragmento seguinte delineia com clareza este fato:

5 A presença do intérprete de LIBRAS é garantida legalmente pelo Art. 23 do Decreto $\mathrm{N}^{\circ} 5.626$, de 22 de dezembro de 2005. 
Com relação à prova, a escrita para mim se torna um pouco mais difícil. Já falei com os professores [sobre adaptações], mas eles dizem que não têm condições, porque se eles abrirem exceção para mim, eles vão ter que abrir para todo mundo. Então, a melhor prova para mim seria a oral (Universitário Cláudio).

Talvez, o não atendimento dos professores à solicitação do universitário Cláudio, que requeria mudança na ferramenta de avaliação pedagógica, deva-se a uma compreensão equivocada do conceito de inclusão pelo coordenador do curso de Educação Física da Instituição "B", que administrava a Faculdade dentro desse princípio e orientava os professores a procederem da mesma forma. Para o coordenador de curso, o conceito de inclusão significava tratar todos os/ as universitários/as com e sem deficiência de forma igualitária, sem qualquer forma de tratamento especial e/ou quaisquer alterações na prática pedagógica. Vejamos a sua compreensão:

Não tem tratamento especial, praticamente as atitudes são normais, essaé a orientação que nós passamos. Os professores já estão todos orientados e já incluem na rotina. Não tem porque tratar diferente. Com relação à prática pedagógica, nas atividades teóricas e nas aulas práticas não há nenhuma diferença. É o processo inclusivo! Você não pode dizer que está trabalhando com a inclusão e usar a exclusão (Coordenador Fabrício).

Ao analisarmos essa concepção do coordenador Fabrício, percebemos que a inclusão era compreendida como aniquiladora das diferenças - todos sendo tratados da mesma forma, independentes de suas diferenças. O que é "um equívoco de ordem ideológica, tendo em vista que a prática discursiva em questão não visa a incluir as diferenças ou tratá-las de modo singular, mas a criar identidades fixas, conservadoras e repetitivas" (CAVALLARI, 2010, p. 01). Dessa forma, as diferenças não seriam respeitadas e, nem tampouco, haveria equiparação das oportunidades de ensino, entre todos os universitários. Consequentemente, o processo de inclusão do/a universitário/a com deficiência seria muito mais complexo, podendo, inclusive, dificultar que o seu direito, no caso, à educação, fosse garantido, com qualidade.

Apesar disso, não podemos desconsiderar que algumas ações estavam sendo proporcionadas, embora elas fossem tímidas e ainda insuficientes. Para que se possa ter ideia dessas intervenções, houve a implantação do Núcleo de Apoio Pedagógico e do Núcleo de Apoio ao Aluno, os quais estavam à disposição da comunidade universitária, conforme podemos evidenciar no fragmento a seguir: 
A inclusão de universitários com deficiência em cursos de Educação Física na cidade de Maceió/AL jurídico

Nós temos o Núcleo de Apoio Psicopedagógico e o Núcleo de Apoio ao Aluno. Não apenas para os alunos portadores de necessidades especiais, mas para todos os alunos (Coordenador Fabrício).

Contudo, ainda que a criação destes núcleos tenha uma significativa relevância para o sistema de ensino, suas ações não foram estendidas para os universitários com deficiência da Instituição "B" - já que nenhum deles fez menção a esse serviço, inclusive o Universitário Cláudio, que apresentava dificuldades pedagógicas. O que nos leva a ponderar sobre a ineficácia desses Núcleos de Apoio à inclusão educacional na Instituição "B".

Ademais, na Instituição em questão verificamos outras iniciativas que, apesar de não contribuírem efetivamente para o processo inclusivo, auxiliavam no processo de formação profissional dos acadêmicos de Educação Física da Instituição "B”, os quais como futuros profissionais, atuarão na Educação Básica e possivelmente também irão lecionar para alunos/as com deficiência ${ }^{6}$. Vejamos:

Tem a Jornada Acadêmica de Educação Física. [Tivemos o] I Congresso Alagoano, ano passado. A professora de Educação Física Adaptada já está [organizando] o VI Encontro de Esporte Adaptado. Temos o vôlei sentado. Tem o II Congresso Alagoano, [que] tem as oficinas internas para os alunos, jogos, e no congresso terão partes que tratam sobre os alunos com deficiência (Coordenador Fabrício).

Aqui no $8^{\circ}$ período [da Faculdade de Educação Física] tem a disciplina de LIBRAS (Universitária Mickaela).

É importante destacar, nesses excertos, que o direcionamento do processo de formação profissional em uma perspectiva inclusiva, na Instituição "B", estava enviesado para ações isoladas - oferta de disciplinas de Libras e de Educação Física Adaptada, assim como, para a organização de eventos científico-esportivos que tratam da temática da atividade física para pessoas com deficiência. Embora estas ações apresentem suas devidas importâncias, esta temática não perpassava todo o currículo dos cursos de formação dos professores em Educação Física. Sobre este ponto, é importante entender que não podemos limitar o encargo de todo o processo de formação na perspectiva

6 A União, os estados e os municípios estão sendo convocados a reorganizar os seus sistemas de ensino com base nos pressupostos do paradigma da educação inclusiva, que são estabelecidos pela Declaração de Salamanca (UNESCO, 1994), da qual o Brasil é consignatário. 
inclusiva para determinadas disciplinas e/ou eventos científicos (SIQUEIRA; SANTANA, 2010). Antes, esta responsabilidade deve estar a cargo de todos os partícipes da comunidade acadêmica, os quais necessitam compreender, em suas atividades, a diversidade humana.

\section{Considerações finais}

Os resultados obtidos com esta pesquisa sobre o processo de inclusão de universitários com deficiência em cursos de Graduação em Educação Física da cidade de Maceió/AL permitem-nos afirmar que a participação desse público na educação superior estava ainda muito condicionada às suas capacidades de adaptação a ambientes não inclusivos, os quais apresentavam inúmeros impedimentos, que dificultavam o sucesso educacional, deixando os/as universitários/ as com deficiência vulneráveis à exclusão educacional. Esta realidade exigia muitos esforços deles/as próprios/as e de seus/suas colegas de classe para manter-se na Educação Superior. Por esta razão, é crucial que as instituições pesquisadas (re)pensem a forma com que têm encarado a inclusão no ambiente da sua instituição, e que, além disso, planejem e executem ações que contribuam para a efetivação do processo de inclusão em seu estabelecimento de ensino. Assim, acreditamos que as instituições estudadas estariam mais preparadas para garantir o processo de ensino-aprendizagem do/a universitário/a com deficiência em uma perspectiva da educação inclusiva.

\section{Referências}

ALVES-MAZZOTTI, Alda Judith. Usos e abusos do estudo de caso. Cadernos de Pesquisa, São Paulo, v. 36, n. 129, p. 637-651, set./dez, 2006.

ANDRADE, Martha Sahade de Andrade; PACHECO, Marina Locatelli; FARIAS. Sandra Sâmara Pires. Pessoas com deficiência rumo ao processo de inclusão na educação superior. Revista Conquer, Barreiras, BA, v. 10, n. 12, p. 01-05, 2006.

BARDIN, Laurence. Análise de Conteúdo. São Paulo: Edições 70, 2011.

BRASIL. Ministério da Educação. Aviso Circular no 277/MEC/GM

de 08 de maio de 1996. Dirigido aos Reitores das IES, solicitando a execução adequada de uma política educacional dirigida aos portadores de necessidades especiais. Disponível em: $<$ http://www.tucurui.ifpa.edu.br/files/ aviso277.pdf $>$. Acesso em: 10 de fevereiro de 2013. 
A inclusão de universitários com deficiência em cursos de Educação Física na cidade de Maceió/AL jurídico

BRASIL. Ministério da Educação. Portaria no 3.284 de 07 de novembro de 2003. Dispõe sobre requisitos de acessibilidade de pessoas portadoras de deficiências, para instruir os processos de autorização e de reconhecimento de cursos e de credenciamento de instituições. Disponível em: $<$ http://portal. mec.gov.br/seesp/arquivos/pdf/port3284.pdf > . Acesso em: 14 de fevereiro de 2013.

. Ministério da Educação. Decreto no 5626, de 22 de dezembro de 2005. Regulamenta a Lei $n^{\circ}$. 10.436, de 24 de abril de 2002, que dispõe sobre a Língua Brasileira de Sinais - Libras, e o art. 18 da Lei no 10.098 de 19 de dezembro de 2000. Brasília, 2005. Disponível em: <http://www. planalto.gov.br/ccivil_03/_ato2004-2006/2005/decreto/d5626.htm >. Acesso em: 14 de fevereiro de 2013 .

2010.

. INEP. Censo de Educação Superior 2010. Brasília: MEC/CNE,

. Portal Brasil. Matrículas de pessoas com deficiência em

Universidades. Brasília: MEC, 2012a. Disponível em: $<$ http://www.brasil. gov.br/noticias/arquivos/2012/10/02/ensino-superior-do-brasil-tem-recordede-matriculas-nos-ultimos-anos>. Acesso em: 19 de dezembro de 2012.

. Ministério da Educação. Sistema e-MEC: Instituições de Educação Superior e Cursos Cadastrados - 2012. Brasília: MEC, 2012b. Disponível em: <http://emec.mec.gov.br/>. Acesso em: 30 de agosto de 2012.

CALHEIROS, David dos Santos; FUMES, Neiza de Lourdes Frederico. $\mathrm{O}(\mathrm{A})$ aluno(a) com deficiência nas instituições de ensino superior da cidade de Maceió/AL. Debates em Educação, Maceió, v. 3, n. 5, p. 01-14, jan./jun, 2011.

CARDOSO, Tereza Cristina Rodrigues; BRAGA, Evellyn Romão Lorenço Rasmann. Inclusão de portadores de necessidades especiais no mercado de trabalho brasileiro. Anuário da Produção de Iniciação Científica Discente, Anhanguera, SP, v. 12, n. 14, p. 231-239, 2009.

CAVALLARI, Juliana Santana. O equívoco no discurso da inclusão: o funcionamento do conceito de diferença no depoimento de agentes educacionais. Revista Brasileira de Linguística Aplicada, Belo Horizonte, v. 10, n. 03, p. 667-680, 2010. 
CRUZ, José Ildon Gonçalves; DIAS, Tárcia Regina da Silveira. Trajetória escolar do surdo no ensino superior: condições e possibilidades. Revista Brasileira de Educação Especial, Marília, v.15, n. 01, p. 65-80, 2009.

DIAS, Solange Tomé Gonçalves; SILVEIRA, Giovanna Lobianco; MUSIS, Carlo Ralph de. Um olhar sobre as dificuldades da inclusão presentes na escola e na sociedade. In: SEMINÁRIO EDUCAÇÃO, 1., Cuiabá. Anais ... Cuiabá: Gráfica Pak Multiídia, 2008. p. 01-11.

FLICK, Uwe. Introdução à pesquisa qualitativa. Porto Alegre: Artmed, 2009.

MAGALHÃES, Rita de Cássia Barbosa Paiva; FERREIRA, Francisca Amélia Bezerra; LESSA, Juliana Ponce de Leão; SILVA, Maria Cristiane. Perfil do pedagogo e os desafios da educação inclusiva: a perspectiva de gestores de um curso de Pedagogia. In: CONGRESSO BRASILEIRO DE EDUCAÇÃO ESPECIAL, 3., São Carlos. Anais .... São Carlos: UFSCAR, 2008. p. 4-274.

MARTINS, Gilberto Andrade. Estudo de caso: uma reflexão sobre a aplicabilidade em pesquisas no Brasil. Revista de Contabilidade e Organizações, Ribeirão Preto, SP, v. 2, n. 2, p. 09-18, jan/abr, 2008.

SANTOS, Soraya Dayana Guimarães; VIANA, Márcia Rafaella Graciliano dos Santos; FUMES, Neiza de Lourdes Frederico. Os desafios do acesso e permanência das pessoas com deficiência na Universidade Federal de Alagoas. In: COLÓQUIO INTERNACIONAL SOBRE EDUCAÇÃO SUPERIOR, 1, Feira de Santana. Anais ... Feira de Santana: UEFS, 2008. p. 01-10.

\section{SANTOS, Soraya Dayana Guimarães. Autoconfrontação e o processo de} inclusão: (re)vendo a atividade docente na educação superior. 2011. 131f. Dissertação (Mestrado em Educação Brasileira) - Centro de Educação, Universidade Federal de Alagoas, Maceió, 2011.

SIQUEIRA, Inajara Mills; SANTANA, Carla da Silva. Propostas de acessibilidade para a inclusão de pessoas com deficiências no ensino superior. Rev. bras. educ. espec., Marília, SP, v.16, n.1, p. 127-136, jan./abr, 2010.

VARGAS, Gardia Maria Santos. A Inclusão no Ensino Superior: a experiência da disciplina Prática Pedagógica - Prática de Ensino de turma de 
alunos cegos e com baixa visão. Rev. Ponto de vista, Florianópolis, SC, v. 8, n. 8, p. 131-138, 2006.

UNESCO. Declaração de Salamanca: Princípios, Política e Prática em Necessidades Educacionais Especiais. Paris: UNESCO, 1994.

YUNES, Maria Angela Mattar; SZYMANSKI, Heloísa. Entrevista reflexiva \& grounded-theory: estratégias metodológicas para compreensão da resiliência em famílias. Revista Interamericana de Psicología/ Interamerican Journal of Psychology, Porto Alegre, RS, v. 39, n. 3, p. 431438, 2005.

David dos Santos Calheiros - Universidade Federal de Alagoas Maceió| AL | Brasil. Contato: david_calheiros@yahoo.com Neiza de Lourdes Frederico Fumes - Universidade Federal de Alagoas Maceió | AL | Brasil. Contato: neizaf@yahoo.com e aprovado em 18 de dezembro de 2013. 
